\title{
Gastrointestinal defects in gallstone and cholecystectomized patients
}

\author{
Agostino Di Ciaula $^{1}$ (D) | Emilio Molina-Molina ${ }^{2}$ (D) $\mid$ Leonilde Bonfrate $^{2,3}$ (D) $\mid$ \\ David Q.-H. Wang ${ }^{4}$ (D) | Dan L. Dumitrascu ${ }^{5}$ (D) | Piero Portincasa ${ }^{2}$
}

${ }^{1}$ Division of Internal Medicine, Hospital of Bisceglie, ASL BAT, Bisceglie, Italy

${ }^{2}$ Department of Biomedical Sciences and Human Oncology, Clinica Medica "A.

Murri", University of Bari Medical

School, Bari, Italy

${ }^{3}$ Division of Geriatrics and Gerontology, Hospital "Miulli", Acquaviva delle Fonti, Italy

${ }^{4}$ Department of Medicine, Division of Gastroenterology and Liver Diseases,

Marion Bessin Liver Research Center, Albert Einstein College of Medicine, Bronx, New York

${ }^{5}$ 2nd Department of Internal Medicine, "Iuliu Hatieganu" University of Medicine and Pharmacy, Cluj-Napoca, Romania

\section{Correspondence}

Piero Portincasa, Clinica Medica "Augusto

Murri", Department of Biomedical

Sciences and Human Oncology,

University of Bari Medical School, Bari, Italy.

Email: piero.portincasa@uniba.it

\begin{abstract}
Background and aim: Several gallstone patients complain of dyspeptic symptoms, irrespective of the presence of typical colicky pain. Symptoms often persist after a cholecystectomy. Systematic studies on dyspepsia and dynamic gastrointestinal motor function are missing in gallstone patients with preserved gallbladder or after a cholecystectomy.

Materials and methods: Forty-six gallstone patients (age $55 \pm 2$ years; $15 \mathrm{M}$, $31 \mathrm{~F}$ ) and 24 cholecystectomized patients (age $57 \pm 2$ years; 6M, 18F) (no difference in type and volume of gallstones between the two groups) were compared against a group of 65 healthy controls (age $51 \pm 2$ years; 30M, 35F). Dyspepsia occurring in the prior months was assessed by a questionnaire, gastric and gallbladder emptying by functional ultrasonography and orocecal transit time by a hydrogen breath test using a lactulose-enriched standard liquid meal.

Results: Gallstone patients had significantly greater dyspepsia, fasting and residual gallbladder volumes, and slower gallbladder emptying, gastric emptying and small intestinal transit time than controls. In cholecystectomized patients, gastric emptying further delayed, compared to gallstone patients and controls.

Conclusion: Gallstone patients with the gallbladder "in situ" or after a cholecystectomy display dyspeptic symptoms. Symptoms are associated with multiple gastrointestinal motility defects involving the gallbladder, stomach and small intestine. After cholecystectomy, gastric emptying worsens.
\end{abstract}

\section{K E Y W O R D S}

breath test, cholelithiasis, dyspepsia, motility, orocecal transit time, small intestine, ultrasonography

\section{1 | INTRODUCTION}

Gallstone patients are amongst the most admitted patients to European hospitals, ${ }^{1}$ and the socioeconomic costs of symptomatic uncomplicated or complicated gallstone disease are always on the rise. In developed countries, about $20 \%$ of adults have gallstones, ${ }^{2}$ and the incidence rate increases by $0.60 \%-1.39 \%$ per year. ${ }^{3}$ Gallstone prevalence increases along with aging and is higher in women than in men. ${ }^{4}$ Cholesterol gallstones are mainly made of cholesterol monohydrate crystals, and in the Western society, they account for approximately $75 \%-80 \%$ of the gallstones. ${ }^{4-6}$ In the remaining $20 \%-25 \%$, gallstones are a black pigment formed by polymerized calcium bilirubinate or brown pigment stones growing in the gallbladder or in the infected extrahepatic or intrahepatic bile ducts, respectively. ${ }^{7}$ 
Cholesterol gallstones frequently include several metabolic abnormalities, ranging from insulin resistance, visceral adiposity expansion, overweight, obesity, type 2 diabetes, or metabolic syndrome, ${ }^{8,9}$ coronary heart disease, ${ }^{10}$ risks for cardiovascular disease and cancer. Other abnormalities are independent of the aforementioned risk factors. ${ }^{10-12}$

Appropriate therapy, either medical or mainly surgical (cholecystectomy), is necessary in about $20 \%$ of those who suffer from gallstones, because of colicky pain or complications (such as acute cholecystitis, gallbladder empyema and acute pancreatitis) ${ }^{13,14}$ developing during a lifetime. Gallstone patients may also complain of vague or specific dyspeptic symptoms, likely unrelated to the physical presence of gallstones. ${ }^{4}$ Instead, dyspeptic symptoms might originate from a different mechanism including motility defects (ie intestine, stomach and oesophagus), food intolerance, changes of gut microbiota, self-perception, etc.

Nonspecific gastrointestinal symptoms can also appear in about $10 \%$ of patients after cholecystectomy, but the origin of these disturbances is still unclear. ${ }^{15}$ The aim of this study was therefore to evaluate the coexistence of motor disorders of the gastrointestinal tract along with dyspeptic symptoms, in patients with a gallbladder "in situ" and in a group of matched patients after a cholecystectomy.

\section{2 | MATERIALS AND METHODS}

\section{1 | Subjects}

The study comprised 46 gallstone patients with the gallbladder "in situ" and 24 cholecystectomized patients operated for symptomatic gallstone disease. A group of 65 matched healthy subjects served as the control group. The three subgroups were homogeneous for age and body mass index (Table 1). Epidemiological and clinical features and ultrasonographic appearance of gallstones stones were highly suggestive of cholesterol cholelithiasis.

Gallstones in the group with the gallbladder "in situ" were small and occupied invariably less than $30 \%$ of the fasting gallbladder volume, a safe condition that prevents major mechanical obstructions during postprandial

TABLE 1 Clinical characteristics of enrolled subjects

\begin{tabular}{|llll|} 
& $\begin{array}{l}\text { Control } \\
\text { subjects }\end{array}$ & $\begin{array}{l}\text { Gallstone } \\
\text { patients }\end{array}$ & $\begin{array}{l}\text { Cholecystectomized } \\
\text { patients }\end{array}$ \\
\hline Number & 65 & 46 & 24 \\
\hline Age $(\mathrm{y})$ & $51 \pm 2$ & $55 \pm 2$ & $57 \pm 2$ \\
\hline Males:Females & $30: 35$ & $15: 31$ & $6: 18$ \\
\hline BMI $\left(\mathrm{kg} / \mathrm{m}^{2}\right)$ & $25.0 \pm 0.3$ & $26.4 \pm 0.6$ & $25.4 \pm 0.8$ \\
\hline
\end{tabular}

BMI, body mass index.

Data expressed as mean \pm standard error. gallbladder motility studies. ${ }^{16-19}$ Invariably, fasting gallbladder volume has to be greater than $12 \mathrm{~mL}$, a safe cut-off ruling out hypoplasic, contracted, severely or chronically inflamed gallbladders. ${ }^{20}$ In addition, the gallbladder wall thickness had to be less than $3 \mathrm{~mm}$ to rule out ongoing inflammatory changes, and the gallbladder shape had to be regularly pear-shaped, to simplify volume measurements.

All gallstone patients (either with gallbladder "in situ" or cholecystectomized) had been symptomatic, that is, describing one or more episodes of typical colicky pain in the last 18-24 months. ${ }^{13,21}$ None of the gallstone patients had developed pain in the last eight weeks (a condition potentially able to interfere with motility studies, due to a persisting inflamed gallbladder wall). Cholecystectomized patients had undergone a laparoscopic cholecystectomy within 18-24 months before recruitment. The macroscopic analysis of stones, as well as the microscopic analysis of bile, confirmed that stones were mainly made of cholesterol. $^{22}$

None of enrolled patients had diabetes or any other clinical or pharmacological condition potentially able to influence the indices of gallbladder, gastric and intestinal motility examined in the study.

Healthy subjects had a negative record for major surgeries, for drug intake in the last week capable of modifying the gallbladder and gastrointestinal motor function, and pregnancy was absent in all women.

All participants signed a written informed consent before entry. The studies had approval of the Human Subjects Committees at the Bari University Medical School (Bari, Italy), as per the ethical guidelines of the 1975 Declaration of Helsinki.

\section{2 | Assessment of dyspepsia}

Dyspepsia was quantified by a specific questionnaire according to Buckley et $\mathrm{al}^{23}$ with a score describing severity, frequency and duration of four different symptoms: pain, epigastric burning, belching and a sense of postprandial fullness (maximum score $=48$ ). The score referred to the worst perception of symptoms over the past 12 months in control, gallstone patients and cholecystectomized patients. In gallstone patients, the description of the symptom score was independent on episodes of colicky pain (if any). The value of 8 represented a normal upper limit. ${ }^{24}$

\section{3 | Test meal}

The standard test meal (Nutridrink $^{\circledR}$; Nutricia, Milano, Italy) consisted of $200 \mathrm{~mL}$ liquid suspension containing $12 \mathrm{~g}(20 \%)$ protein, $11.6 \mathrm{~g} \mathrm{(19 \% )}$ fat and $36.8 \mathrm{~g} \mathrm{(61 \% )} \mathrm{car-}$ bohydrates for a total of $300 \mathrm{kcal}, 1260 \mathrm{~kJ}, 455 \mathrm{mOsm} / \mathrm{L}$, energy density $1.5 \mathrm{Kcal} / \mathrm{mL}$, pH 6.5 . 


\subsection{Ultrasonographic studies of gallbladder and gastric emptying}

The ultrasound equipment consisted of a $3.5 \mathrm{MHz}$ convex probe (AU 450, Ansaldo-Hitachi, Genoa and Noblus Hitachi, Japan). The study included the simultaneous examination of gallbladder and gastric emptying. ${ }^{18,25-29}$ Subjects had to fast for at least 12 hours, and measurements were taken in a seated position for 120 minutes. Immediately before and during the examination, subjects could not smoke and drink coffee or soft drinks to avoid interference with the gallbladder and gastric kinetics.

The gallbladder volume was measured according to the ellipsoid formula ${ }^{30,31}$ as fasting gallbladder volume, postprandial volumes taken every 10-15 minutes and minimum residual volume during 120 minutes. Gallbladder half-emptying time was the time when the gallbladder reached $50 \%$ emptying.

For the stomach, the fasting antral area was measured (mean of two measurements at times -5 and 0 minutes before the start of the meal). Postprandial antral areas were calculated immediately after ingestion of the test meal and then at regular time intervals (5-15 minutes) for $120 \mathrm{~min}$ utes. Gastric half-emptying time was the time when the stomach reached 50\% emptying and calculated from the emptying curve (area/time). ${ }^{26-29}$

\subsection{Orocecal transit time}

Subjects followed a diet restricted in fermentable foods and were in "wash-out" for at least 10 days from drugs or manoeuvres (ie enemas) that could interfere with the intestinal microbiota or intestinal kinetics. A portable detector (EC60 Gastrolyzer $^{\circledR}$, Bedfont, UK) was used to measure the values of hydrogen $\left(\mathrm{H}_{2}\right)$ in the fasted breath and at 10 minutes intervals up to 240 minutes after ingestion of $10 \mathrm{~g}$ of crystalline lactulose contained in $15 \mathrm{~mL}$ Duphalac ${ }^{\circledR}$ (Mylan, Milano, Italy), dissolved in the standard liquid meal. Orocecal transit time (OCTT) was the time required to observe an increase in $\mathrm{H}_{2}$ in the expired air by at least 10 parts per million (ppm) on the minimum $\mathrm{H}_{2}$ fasting level, and for at least three consecutive time points. ${ }^{27,32-34}$

\subsection{Statistical analysis}

The results are mean \pm standard errors (SEM). The oneway ANOVA followed by the Fisher's LSD multiple comparison test was used to assess the differences between control, gallstone patients and cholecystectomized patients. Student's $t$ test compared gallbladder motility between control and gallstone patients. Significant differences were considered with a probability $(P)$ of less than $0.05 .{ }^{35} \mathrm{Cal}-$ culations were performed with the NCSS 10 Statistical
Software (2015) (NCSS, LLC. Kaysville, UT, USA, ncss.com/software/ncss).

\section{3 | RESULTS}

\section{1 | Dyspeptic symptoms}

The score of dyspepsia in gallstone patients and cholecystectomized patients was almost threefold increased and significantly $(P<0.0001)$ greater than the score of the control group, but comparable between the two groups of patients (Table 2).

The ingestion of the test meal was uneventful, and during the motility studies, the compliance was excellent in all subjects

\section{2 | Gallbladder motility}

The functional ultrasonographic study of time-dependent changes of gallbladder volume in the groups of gallstone patients and control showed that both fasting and postprandial volumes increased continuously by about $33 \%$ in gallstone patients throughout the emptying curve. Consequently, the residual (minimal) volume increased by 66\% (absolute value) and 29\% (normalized value) and halfemptying time almost doubled, as compared to the controls (Table 2, Figure 1A-C).

\section{3 | Gastric motility}

The functional ultrasonographic study of time-dependent changes of antral areas appears in Table 2, Figure 2A-C. Fasting antral areas were comparable across the three groups (mean range $3.4-3.6 \mathrm{~cm}^{2}$ ). Following the ingestion of the $200 \mathrm{~mL}$ liquid test meal, antral dilation invariably occurred within 5 minutes and was comparable across groups (mean range $11.7-12.2 \mathrm{~cm}^{2}$ ). Gastric emptying was incomplete, delayed throughout the 120 minutes in both gallstone and cholecystectomized patients, as compared to the control group. However, the gastric emptying defects were more evident in cholecystectomized patients. Overall, in patients the score of dyspeptic symptoms was unrelated to the timing of antral emptying (half-emptying time, data not shown).

\subsection{Orocecal transit time}

For the small intestine, concentrations of $\mathrm{H}_{2}$ in expired air showed a progressive time-dependent increment in the three groups. This finding is a reliable marker of bacterial fermentation of lactose in the distal gut. However, the extent of $\mathrm{H}_{2}$ production by gut microbiota was greater in the control group rather than gallstone and cholecystectomized patients (Figure 3). OCTT was 50\%-59\% delayed in gallstone and 
TABLE 2 Results from the questionnaire for dyspepsia and gastrointestinal motility

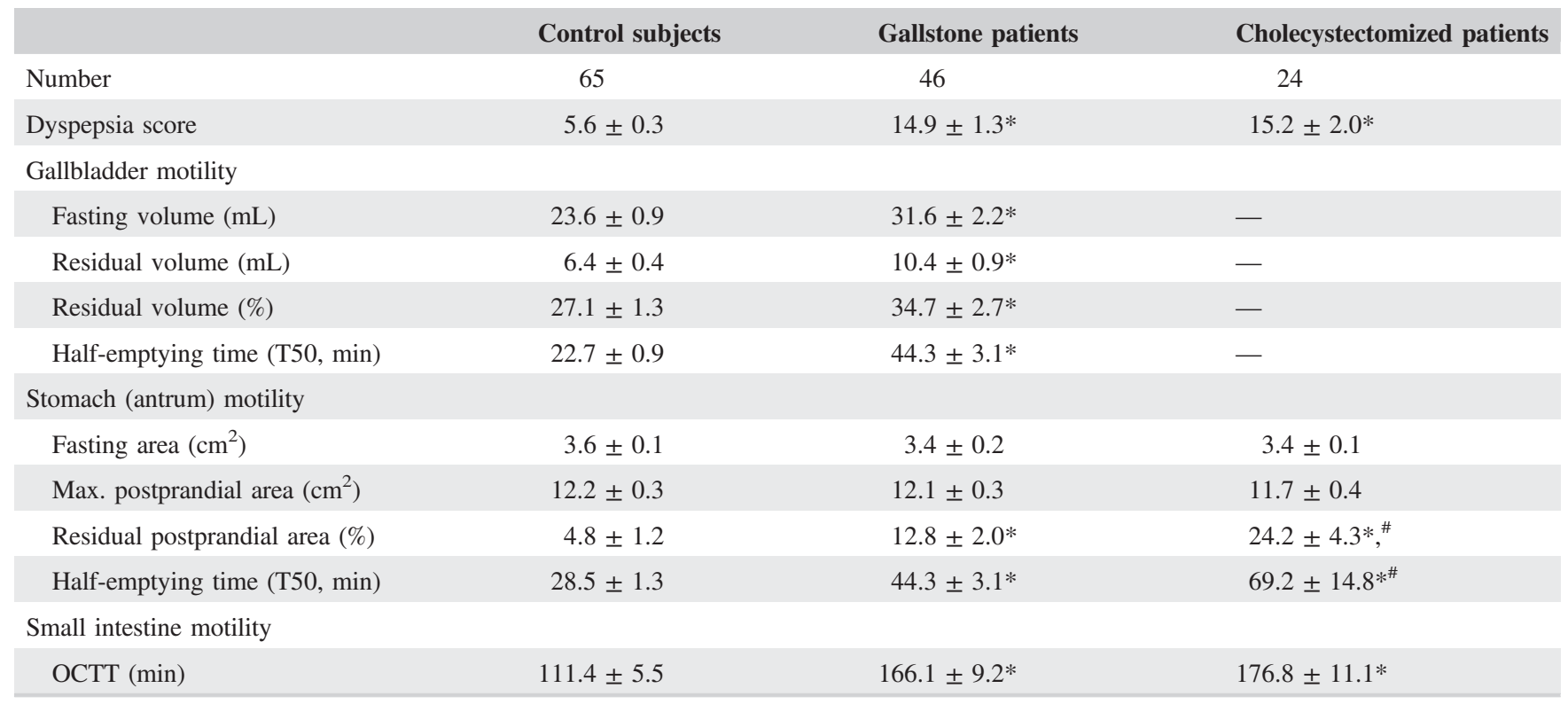

OCTT, orocecal transit time.

Data expressed as mean \pm standard error. Significantly different from control: ${ }^{*} P<0.05$; significantly different from gallstone ${ }^{\#} P<0.05$.

cholecystectomized patients, as compared to healthy controls (Table 2, Figure 3A, B). A trend towards a progressively reduced area under curve (AUC) of $\mathrm{H}_{2}$ levels in exhaled air was recorded between controls, gallstone and cholecystectomized patients, although the difference between the three subgroups was not significant (Figure 3C).

\section{4 | DISCUSSION}

The present study shows that gallstone patients often complain of dyspeptic symptoms, while exhibiting diffuse motility defects, as compared to healthy subjects. The dysmotility profile involves the gallbladder, the stomach and the small intestine, and deteriorates in cholecystectomized patients, even years after surgery.

The extent of dyspeptic symptoms occurring in the previous year was similar in gallstone patients with or without "in situ" gallbladder. Moreover, we confirm that the mean score of dyspepsia is extremely low in control subjects, as shown in previous studies. ${ }^{24,36}$

The ingestion of the liquid test meal was not associated with dyspeptic symptoms (especially fullness) throughout the observation time. Likely, the moderate volume $(215 \mathrm{~mL})$ and the isosmotic/fat composition of the test meal $(11.6 \mathrm{~g}=19 \%)$ fat, $300 \mathrm{kcal}$ was not sufficient to trigger upper gastrointestinal symptoms in these groups of subjects. Larger volumes, higher caloric content, fat content or meal type (ie semisolid vs liquid), might explain the symptomatic response of a test meal. ${ }^{27}$ This was the case in chronic alcoholic patients, ${ }^{36}$ scleroderma patients and dyspeptic patients without dyspepsia. ${ }^{24}$
The delayed gastric emptying can explain only in part these findings. In fact, the extent of dyspepsia (as measured by a score) and the timing of postprandial gastric emptying (ie, half-emptying time) were apparently unrelated in the present group of patients. Additionally, cholecystectomized patients showed the worst indices of gastric emptying, as compared with gallstone patients, although the score of dyspepsia was similar in the two subgroups. In line with these findings, and in accordance with international guidelines, this study confirms that dyspepsia is not specifically related to the presence of gallstones. $^{7,13,37,38}$ Furthermore, studies conducted on the general population found no greater prevalence of dyspepsia in gallstone patients. ${ }^{4,39}$ Dyspeptic symptoms might rather originate from multiple coexisting motility defects in gallstone patients, likely persisting after a cholecystectomy. This is the case in this study and in another study, which examined gallstone patients before and after a cholecystectomy. ${ }^{40}$ Indeed, dyspepsia persisted in a consistent number of patients. Indirectly, we confirm that the colicky pain is a specific symptom clinically linked to the presence of uncomplicated gallstones, and it should be considered in a group of patients who are scheduled for a cholecystectomy.

On the other hand, a study found that cholecystectomy is associated with a series of nonspecific gastrointestinal symptoms, especially in the first three years after surgery. Findings include a wide panel of gastric disorders such as peptic ulcer, hiatus hernia and gastro-oesophageal reflux. Misdiagnosis of some pre-existing diseases, however, is possible. $^{15}$ 

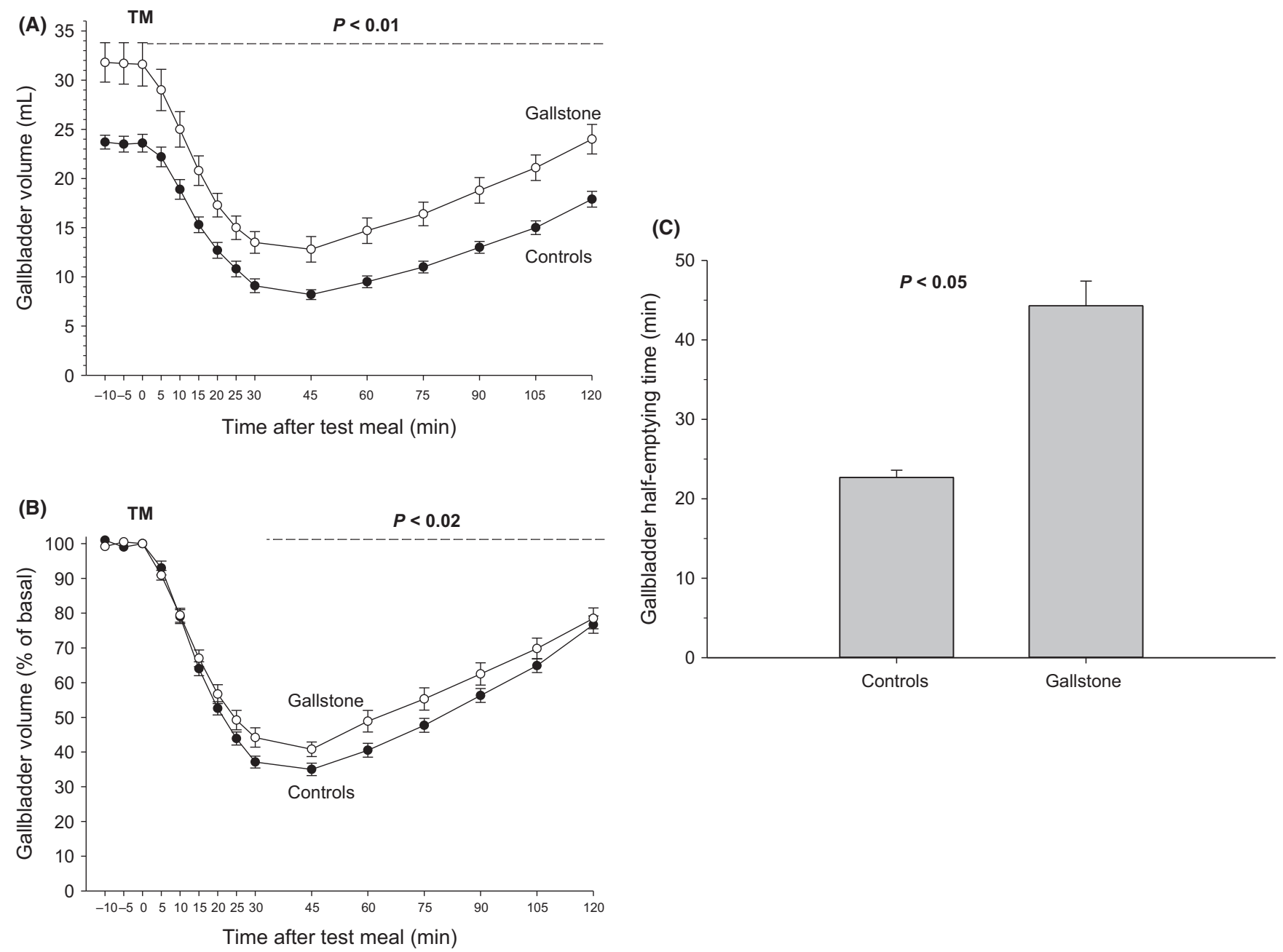

F I G URE 1 Gallbladder motility studies. Time-dependent changes of fasting and postprandial gallbladder volumes and half-emptying time in 46 gallstone patients and 65 control healthy subjects. Symbols indicate means, and vertical lines are standard errors. TM = test meal administered. A, Absolute values in $\mathrm{mL}$ with significant difference $(P<0.01)$ between the two curves between 0 and 120 min; B, Percentage of fasting gallbladder volume with significant difference $(P<0.02)$ between 30 and 75 min; C, Half-emptying time in min. Significant difference $(P<0.05)$ between groups

The presence of an altered postprandial gastric emptying occurs either with or without "in situ" gallbladder, suggesting that this defect is independent of the physical presence of gallstones, and possibly linked with mechanisms, which also influence gastrointestinal motility at different levels of the gastrointestinal tract. ${ }^{41}$ The extent and timing of gastric emptying worsen after gallbladder removal, pointing to the presence of altered pathways involving bile flow and/or signalling molecules. At variance with the present study, an early report found improved gastric emptying following cholecystectomy. ${ }^{40}$ Differences in selection and number of patients, characteristics of study design (ie two separate groups in this study vs pre-postcholecystectomy in the study by Ibrarullah $^{40}$ ) and duration of follow-up might account for such differences.

The possibility exists, however, that some significant findings found in the present series of cholecystectomized patients could be partly due to cholecystectomy itself involving neuro-hormonal and anatomic changes. Post-operative ileus, for example, is a predictable, self-terminating event, occurring after most general anaesthetic procedures. ${ }^{42}$ However, cholecystectomy might induce effects in the medium- and long-term period but studies are somewhat heterogeneous. Symptoms of postcholecystectomy syndrome are likely not related to increased duodenogastric reflux after surgery. ${ }^{43}$ Cholecystectomy, however, may cause an exaggerated meal-stimulated cholecystokinin (CCK) response, a factor involved in relaxation of the lower oesophageal sphincter and likely increased incidence of gastro-oesophageal reflux. ${ }^{44}$ In the dog, fed-state motility (but not fasted gastrointestinal motility) was the only parameter improving after laparoscopic cholecystectomy, compared to open cholecystectomy. ${ }^{45}$ In a small, short-term study performed in five women at baseline, and six months after surgery, laparoscopic cholecystectomy suppressed the normal inhibitory effect of pharmacological doses of CCK 

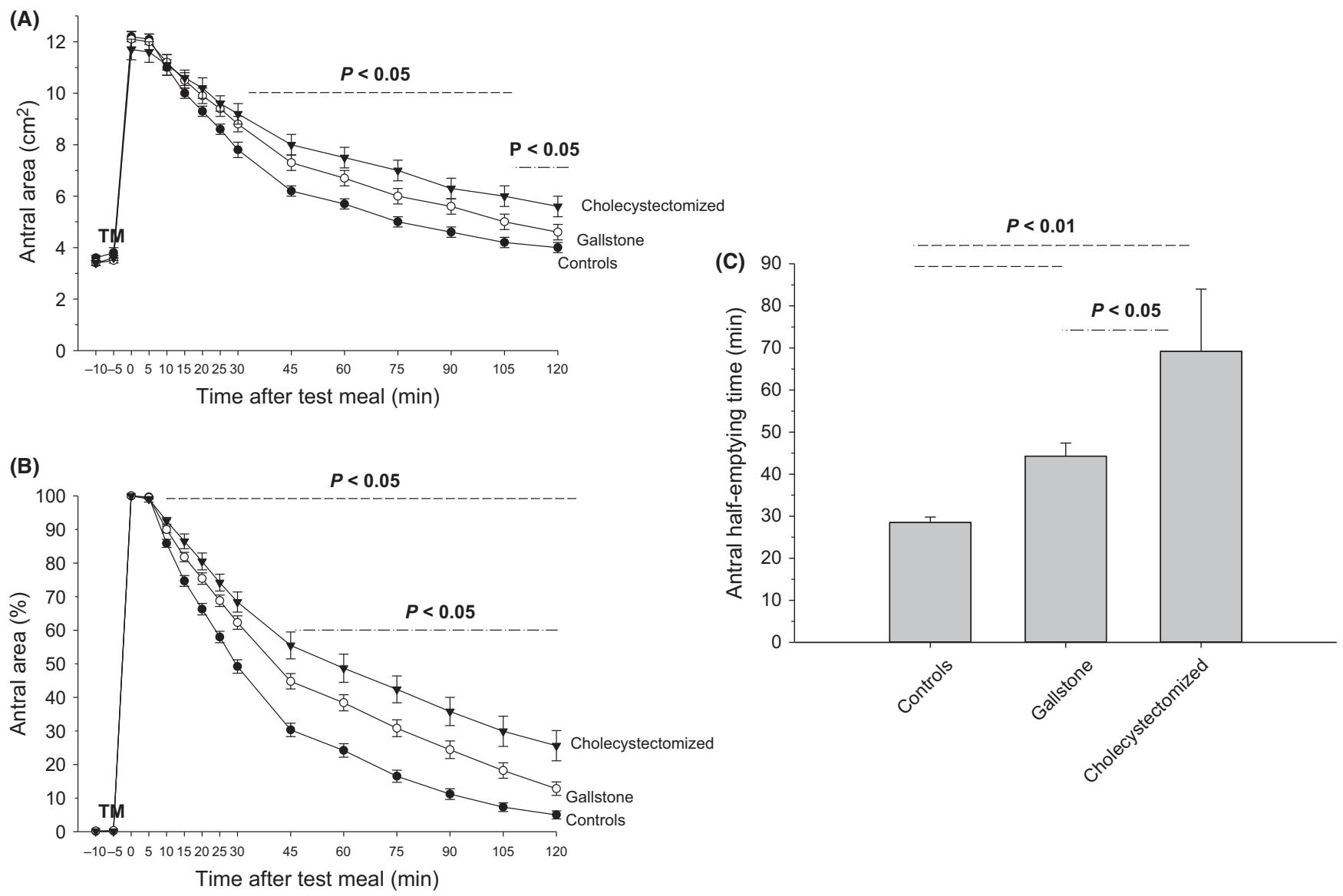

F I G URE 2 Gastric emptying studies. Time-dependent changes of fasting and postprandial antral areas and half-emptying time in 46 gallstone patients, 24 cholecystectomized patients and 65 control healthy subjects. Symbols indicate means, and vertical lines are standard errors. $\mathrm{TM}=$ test meal administered. A, Absolute values in $\mathrm{cm}^{2}$ with significant difference $(P<0.05)$ between gallstone patients, cholecystectomized patients and controls (----) from 25 to $105 \mathrm{~min}$, and between gallstone patients and cholecystectomized patients (-.---) between 105 and 120 min; B, Percentage of maximal antral area with significant difference $(P<0.05)$ between gallstone patients, cholecystectomized patients and controls (----) between 10 and $120 \mathrm{~min}$, and between gallstone patients and cholecystectomized patients (-.-.-) between 45 and 120 min; C, Half-emptying time in min. Significant differences $P<0.01$ vs controls (---) and $P<0.05$ vs gallstone patients (-.-.-)

on the Oddi sphincter. Sphincter denervation might explain such findings. ${ }^{46}$ From the above-mentioned results, it is clear that further prospective studies are necessary to enrol a larger number of gallstone patients and examined at different time points before and after gallbladder removal.

All gallstone patients had a small gallstone burden ( $<30 \%$ of fasting volume), a condition unable to affect the gallbladder kinetics directly by obstructing the cystic duct and impeding gallbladder emptying. ${ }^{16,17}$ Major acute and chronic inflammatory changes of the gallbladder wall were absent, as confirmed by a thin gallbladder wall. All gallstone and cholecystectomized patients had suffered from typical colicky pain without known complications of gallbladder disease (ie acute cholecystitis, empyema, biliary pancreatitis, etc). ${ }^{37,38}$ However, we found that gallstone patients displayed increased fasting, postprandial volumes and delayed gallbladder emptying, as compared with controls, suggesting the presence of sluggish gallbladder function and ongoing gallbladder stasis. ${ }^{16}$ Growth of cholesterol gallstones depends on at least five primary pathogenic defects and involves LITH genes and genetic factors, hepatic hypersecretion of cholesterol accumulating in a supersaturated gallbladder bile, rapid phase precipitation of solid cholesterol crystals in bile and gallbladder stasis. This type of visceral stasis is a clear predisposing factor towards accumulation of concentrated supersaturated bile and hypersecretion of mucin gel from the gallbladder epithelium during the immune-mediated gallbladder inflammation. Additional factors involve intestinal cholesterol absorption, defective intestinal motility and changes of the gut microbiota. ${ }^{47,48}$ The presence of a hypomotile gallbladder, both in the fasting state ${ }^{49,50}$ and in response to neurohormonal postprandial stimuli, ${ }^{16,51,52}$ plays an important role. Gallbladder hypomotility, in fact, is one of the major pathogenic factors contributing to the accumulation of excess biliary cholesterol in the gallbladder lumen, ${ }^{47,52}$ as well as precipitation of solid cholesterol crystals, a key step in the further growth of gallstones. ${ }^{48}$ This study assessed 

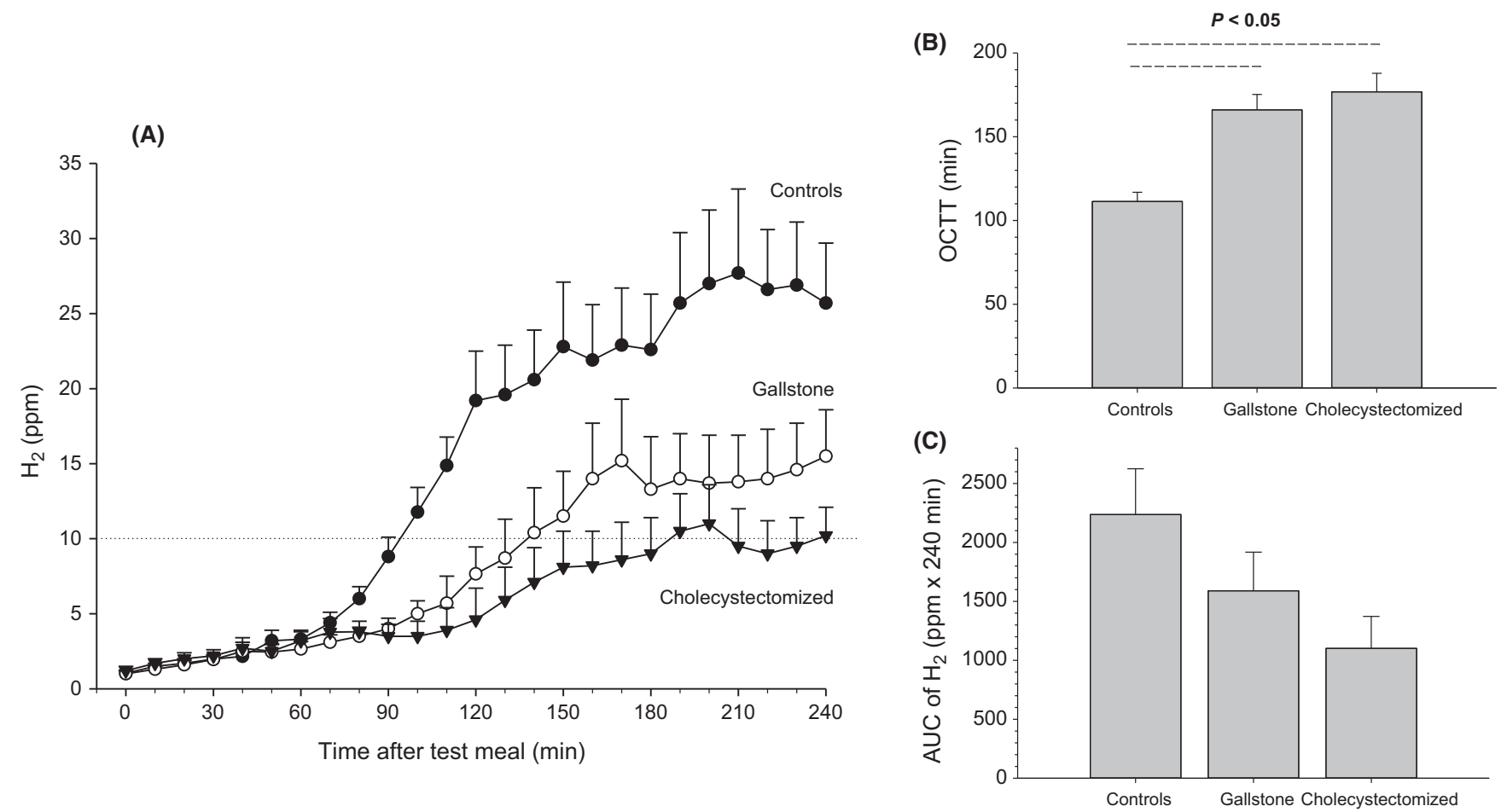

F I G U RE 3 Intestinal transit. A, Time-dependent curves of H2 levels (ppm) in exhaled air in 46 gallstone patients, 24 cholecystectomized patients and 65 control healthy subjects. Symbols indicate means, and vertical lines are standard errors. The horizontal dotted line indicates the cut-off level to document a significant increase in $\mathrm{H}_{2}$ production $(10 \mathrm{ppm})$; B, Orocecal transit time (OCTT). Significant differences $P<0.05$ vs controls (---); C, Area under curve (AUC) of $\mathrm{H}_{2}$ levels in exhaled air (ppm $\times 240 \mathrm{~min}$ )

gallbladder motility in patients with cholesterol gallstones, but a type of intermediate motility defect also exists in patients with pigment stones. ${ }^{53,54}$

Gallbladder kinetics depends on about 60 to $80 \%$ of its reduction on vagal cholecystokinin-mediated mechanisms, which lead to expulsion and increased intraluminal concentrations of bile acids (BA) ${ }^{55} \mathrm{BA}$ recirculation increases following cholecystectomy, and this mechanism may contribute to the increased risk for metabolic syndrome observed after gallbladder removal. ${ }^{55}$ The missing gallbladder function may also explain why several components of metabolic syndrome, such as glucose or lipids homeostasis, are present after a cholecystectomy, mainly due to abnormal metabolic signalling on gene expression, BA/farnesoid $\mathrm{X}$ receptor (FXR) and BA/G-coupled bile acid receptor-1 (GPBAR-1) and fibroblast growth factor 19 (FGF19) axis. ${ }^{56}$

Our results confirm that both gallstone and cholecystectomized patients have a more general impairment of gastrointestinal motility, which also involves the small intestine. Here, we find that OCTT is delayed in response to the test meal containing lactulose, a substrate which becomes fermentable at the level of the cecum, where gut microbiota displays the highest density. ${ }^{57}$

A previous observation reported a significantly delayed OCTT in gallstone patients, an increased prevalence of small intestinal bacterial overgrowth (SIBO), high levels of serum BA and a positive correlation between OCTT and serum BA levels in patients with both gallstones and SIBO ${ }^{58}$ Remarkably, another study found prolonged large intestinal transit and increased levels of biliary deoxycholate in a subgroup of gallstone patients. ${ }^{59}$

This study also shows a trend towards a progressive decrease of fermentation of lactulose, from controls to gallstone and cholecystectomized patients. Although the difference among average AUC values of $\mathrm{H}_{2}$ in expired air did not reach the statistical significance, this trend suggests a reduced overall fermentation capacity of gut microbiota in patients with gallstone disease (with or without "in situ" gallbladder), as compared to healthy subjects. This hypothesis could be confirmed, at least in part, by previous observations describing relevant qualitative differences in gut microbiota between healthy subjects, gallstone patients and cholecystectomized subjects. ${ }^{60-62}$ Further studies are certainly required in order to better explore this possibility.

Delay of intestinal transit, associated with gallbladder hypomotility, should be seen in the context of a wide "intestinal disease", ${ }^{63}$ since a greater proportion of hepatic bile leads to dihydroxylation, partly mediated by the gut microbiota with a consequent increase of the deoxycholate, strongly hydrophobic and cytotoxic BA. The reuptake in the enterohepatic circle of deoxycholate is able to influence 
the phenomena of crystallization and nucleation of biliary cholesterol with greater lithogenic effects. ${ }^{64,65}$

Overall, the results of the present study suggest that patients developing cholesterol cholelithiasis suffer from a type of "pan-enteric" motility defect. ${ }^{63}$ Abnormalities may involve the oesophagus, ${ }^{66}$ the stomach ${ }^{66}$ the small intestine and the colon as well. ${ }^{67-70}$ The link between cholesterol cholelithiasis and obesity ${ }^{28,29}$ and/or diabetes, ${ }^{71}$ as components of the metabolic syndrome, might further deteriorate the overall profile of gastrointestinal motility. ${ }^{52}$ Apparently, the motility defect persists (or worsens as in the case of gastric emptying) after a cholecystectomy.

Further studies should involve a larger number of subjects with gallstones of any type and size, in order to avoid possible biases. In this context, studies should focus on existing links between multiple gastrointestinal motility defects, pathogenic pathways of gallstones, and persisting (or worsening) of symptoms and defects after gallbladder removal.

\section{5 | CONCLUSION}

This study shows that gallstone patients with the gallbladder "in situ" or after cholecystectomy display symptoms of dyspepsia. Symptoms are associated with multiple gastrointestinal motility defects involving increased fasting and residual gallbladder volume, along with delayed gastric and small intestine transit. After a cholecystectomy, gastric emptying worsens.

\section{ACKNOWLEDGEMENTS}

The present paper is written in the context of the FOIE GRAS project, which received funding from the European Union's Horizon 2020 Research and Innovation programme under the Marie Skłodowska-Curie Grant Agreement No. 722619. The authors thank Rosa De Venuto and Paola De Benedictis for their excellent technical assistance. There are no known conflicts of interest associated with this publication and there has been no significant financial support for this work that could have influenced its outcome.

\section{CONFLICT OF INTEREST}

The authors declare that they have no conflict of interest.

\section{ORCID}

Agostino Di Ciaula (iD https://orcid.org/0000-0002-54767376

Emilio Molina-Molina (iD https://orcid.org/0000-0003-43905275
Leonilde Bonfrate (iD https://orcid.org/0000-0002-49557964

David Q.-H. Wang (D) https://orcid.org/0000-0002-54397651

Dan L. Dumitrascu (D) https://orcid.org/0000-0001-5404-

7662

Piero Portincasa (D) https://orcid.org/0000-0001-5359-1471

\section{REFERENCES}

1. Farthing M, Roberts SE, Samuel DG, et al. Survey of digestive health across Europe: final report. Part 1: the burden of gastrointestinal diseases and the organisation and delivery of gastroenterology services across Europe. United European Gastroenterol J. 2014;2:539-543.

2. Portincasa P, Moschetta A, Palasciano G. Cholesterol gallstone disease. Lancet. 2006;368:230-239.

3. Shabanzadeh DM. Incidence of gallstone disease and complications. Curr Opin Gastroenterol. 2018;34:81-89.

4. Attili AF, Carulli N, Roda E, et al. Epidemiology of gallstone disease in Italy: prevalence data of the Multicenter Italian Study on Cholelithiasis (M.I.COL.). Am J Epidemiol. 1995;141:158165.

5. Attili AF, Capocaccia R, Carulli N, et al. Factors associated with gallstone disease in the MICOL experience. Multicenter Italian Study on Epidemiology of Cholelithiasis. Hepatology. 1997;26:809-818.

6. Diehl AK. Epidemiology and natural history of gallstone disease. Gastroenterol Clin North Am. 1991;20:1-19.

7. Lammert F, Gurusamy K, Ko CW, et al. Gallstones. Nat Rev Dis Primers. 2016;2:16024. https://doi.org/10.1038/nrdp.2016.24

8. Di Ciaula A, Garruti G, Wang DQ-H, Portincasa P. Role of insulin resistance in the formation of cholesterol gallstones. In: Wang DQ-H, Portincasa P, eds. Gallstones - Recent Advances in Epidemiology, Pathogenesis, Diagnosis and Management. New York, NY: Nova Science Publishers; 2017:357-372.

9. Shabanzadeh DM, Skaaby T, Sorensen LT, Eugen-Olsen J, Jorgensen T. Metabolic biomarkers and gallstone disease - a population-based study. Scand J Gastroenterol. 2017;52:1270-1277.

10. Lv J, Qi L, Yu C, et al. Gallstone disease and the risk of ischemic heart disease. Arterioscler Thromb Vasc Biol. 2015;35:2232-2237.

11. Zheng Y, Xu M, Heianza Y, et al. Gallstone disease and increased risk of mortality: two large prospective studies in US men and women. J Gastroenterol Hepatol. 2018;33:1925-1931.

12. Shabanzadeh DM, Sorensen LT, Jorgensen T. Gallstone disease and mortality: a cohort study. Int J Public Health. 2017;62:353360.

13. European Association for the Study of the Liver. Electronic address eee. EASL Clinical Practice Guidelines on the prevention, diagnosis and treatment of gallstones. $J$ Hepatol. 2016;65:146-181.

14. Portincasa P, Di Ciaula A, de Bari O, Garruti G, Palmieri VO, Wang DQ. Management of gallstones and its related complications. Expert Rev Gastroenterol Hepatol. 2016;10:93-112. 
15. Isherwood J, Oakland K, Khanna A. A systematic review of the aetiology and management of post cholecystectomy syndrome. Surgeon. 2018, in press, https://doi.org/10.1016/j.surge.2018.04.001

16. Portincasa P, Di Ciaula A, Baldassarre G, et al. Gallbladder motor function in gallstone patients: sonographic and in vitro studies on the role of gallstones, smooth muscle function and gallbladder wall inflammation. J Hepatol. 1994;21:430-440.

17. Portincasa P, Di Ciaula A, Palmieri V, Vendemiale G, Altomare E, Palasciano G. Sonographic evaluation of gallstone burden in humans. Ital J Gastroenterol. 1994;26:141-144.

18. Portincasa P, Colecchia A, Di Ciaula A, et al. Standards for diagnosis of gastrointestinal motility disorders. Section: ultrasonography. A position statement from the Gruppo Italiano di Studio Motilita Apparato Digerente. Dig Liver Dis. 2000;32:160-172.

19. Portincasa P, Moschetta A, Colecchia A, Festi D, Palasciano G. Measurement of gallbladder motor function by ultrasonography: towards for standardization. Dig Liver Dis (già Ital J Gastroenterol Hepatol). 2003;35(Suppl. 3):S56-S61.

20. Fiorucci S, Bosso R, Morelli A. Erythromycin stimulates gallbladder emptying and motilin release by atropine-sensitive pathways. Dig Dis Sci. 1992;37:1678-1684.

21. Schoenfield L, Carulli N, Dowling R, Sama C, Wolpers C. Asymptomatic gallstones: definition and treatment. Gastroenterol Int. 1989;2:25-29.

22. Portincasa P, van Erpecum KJ, Jansen A, Renooij W, Gadellaa M, vanBerge-Henegouwen GP Behavior of various cholesterol crystals in bile from patients with gallstones. Hepatology. 1996;23:738-748.

23. Buckley MJ, Scanlon C, McGurgan P, O'Morain CA. A validated dyspepsia symptom score. Ital $J$ Gastroenterol Hepatol. 1997;29:495-500.

24. Di Ciaula A, Covelli M, Berardino M, et al. Gastrointestinal symptoms and motility disorders in patients with systemic scleroderma. BMC Gastroenterol. 2008;8:7.

25. Stolk MF, van Erpecum KJ, van Berge Henegouwen GP, Kesselring OF, Hopman WP. Gallbladder volume and contraction measured by sum-of-cylinders method compared with ellipsoid and area-length methods. Acta Radiol. 1990;31:591-596.

26. Bolondi L, Bortolotti M, Santi V, Calletti T, Gaiani S, Labo G. Measurement of gastric emptying time by real-time ultrasonography. Gastroenterology. 1985;89:752-759.

27. Diella G, Di Ciaula A, Lorusso MP, et al. Distinct effects of two almond cultivars on agreeability and gastrointestinal motility in healthy subjects: more than mere nutraceuticals. J Gastrointestin Liver Dis. 2018;27:31-39.

28. Di Ciaula A, Wang DQ, Portincasa P. Gallbladder and gastric motility in obese newborns, pre-adolescents and adults. J Gastroenterol Hepatol. 2012;27:1298-1305.

29. Portincasa P, Altomare DF, Moschetta A, et al. The effect of acute oral erythromycin on gallbladder motility and on upper gastrointestinal symptoms in gastrectomized patients with and without gallstones: a randomized, placebo-controlled ultrasonographic study. Am J Gastroenterol. 2000;95:3444-3451.

30. Everson GT, Braverman DZ, Johnson ML, Kern F Jr. A critical evaluation of real-time ultrasonography for the study of gallbladder volume and contraction. Gastroenterology. 1980;79:40-46.

31. Dodds WJ, Groh WJ, Darweesh RM, Lawson TL, Kishk SM, Kern MK. Sonographic measurement of gallbladder volume. AJR Am J Roentgenol. 1985;145:1009-1011.
32. Bond JH Jr, Levitt MD, Prentiss R. Investigation of small bowel transit time in man utilizing pulmonary hydrogen $(\mathrm{H} 2)$ measurements. J Lab Clin Med. 1975;85:546-555.

33. La Brooy SJ, Male PJ, Beavis AK, Misiewicz JJ. Assessment of the reproducibility of the lactulose $\mathrm{H} 2$ breath test as a measure of mouth to caecum transit time. Gut. 1983;24:893-896.

34. Bonfrate L, Krawczyk M, Lembo A, Grattagliano I, Lammert F, Portincasa P. Effects of dietary education, followed by a tailored fructose-restricted diet in adults with fructose malabsorption. Eur J Gastroenterol Hepatol. 2015;27:785-796.

35. Hintze J. NCSS 10 Statistical Software. Number Cruncher Statistical System (NCSS), LLC. Kaysville, Utah, USA, ncss.com/software/ncss, 2015.

36. Di Ciaula A, Grattagliano I, Portincasa P. Chronic alcoholics retain dyspeptic symptoms, pan-enteric dysmotility, and autonomic neuropathy before and after abstinence. J Dig Dis. 2016;17:735-746.

37. Portincasa P, Wang D. Gallstones. In: Podolsky KD, Camilleri M, Fitz JG, Kalloo AN, Shanahan F, Wang TC, eds. Yamada's Textbook of Gastroenterology. Hoboken, NJ: Wiley-Blackwell; 2015:1808-1834.

38. Portincasa P, Wang D. Gallstones. In: Podolsky KD, Camilleri M, Fitz JG, Kalloo AN, Shanahan F, Wang TC, eds. Yamada's Atlas of Gastroenterology. Hoboken, NJ: Wiley-Blackwell; 2016:335-353.

39. Attili AF, De Santis A, Capri R, Repice AM, Maselli S. The natural history of gallstones: the GREPCO experience. The GREPCO Group. Hepatology. 1995;21:655-660.

40. Ibrarullah M, Mittal BR, Aagrawal DK, Das BK, Kaushik SP. Gastric emptying in patients with gallstone disease with or without dyspepsia: effect of cholecystectomy. ANZ $J$ Surg. 1994;64:247-250.

41. Di Ciaula A, Portincasa P. Recent advances in understanding and managing cholesterol gallstones. F1000Res. 2018;7:1529.

42. Bowling TE. Does disorder of gastrointestinal motility affect food intake in the post-surgical patient? Proceedings of the Nutrition Society. 2007;53:151-157.

43. Manifold DK, Anggiansah A, Owen WJ. Effect of cholecystectomy on gastroesophageal and duodenogastric reflux. Am J Gastroenterol. 2000;95:2746-2750.

44. McDonnell CO, Bailey I, Stumpf T, Walsh TN, Johnson CD. The effect of cholecystectomy on plasma cholecystokinin. Am J Gastroenterol. 2002;97:2189-2192.

45. Hotokezaka M, Combs MJ, Mentis EP, Schirmer BD. Recovery of fasted and fed gastrointestinal motility after open versus laparoscopic cholecystectomy in dogs. Ann Surg. 1996;223:413419.

46. Luman W, Williams AJ, Pryde A, et al. Influence of cholecystectomy on sphincter of Oddi motility. Gut. 1997;41:371-374.

47. Wang D, Neuschwander-Tetri BA, Portincasa P. The Biliary System, 2nd ed., Vol. 8. San Rafael, CA: Morgan \& Claypool Life Sciences; 2017:i-178.

48. Di Ciaula A, Wang DQ, Portincasa P. An update on the pathogenesis of cholesterol gallstone disease. Curr Opin Gastroenterol. 2018;34:71-80.

49. Stolk MF, van Erpecum KJ, Smout AJ, et al. Motor cycles with phase III in antrum are associated with high motilin levels and prolonged gallbladder emptying. Am J Physiol. 1993;264:G596600 . 
50. Stolk M, van Erpecum KJ, Samson M, et al. Interdigestive gallbladder emptying, antroduodenal motility and motilin release in cholesterol gallstone patients. In: Stolk M, ed. Pathogenesis of Cholesterol Gallstones. Utrecht: Thesis Universiteit Utrecht; 1993:65-78.

51. Portincasa P, Di Ciaula A, Palmieri VO, Baldassarre G, van Berge-Henegouwen GP, Palasciano G. Enhancement of gallbladder (GB) emptying in gallstone patients after oral cholestyramine. Neth J Med. 1994;45:A36.

52. Portincasa P, Di Ciaula A, Wang HH, et al. Coordinate regulation of gallbladder motor function in the gut-liver axis. Hepatology. 2008;47:2112-2126.

53. Portincasa P, Di Ciaula A, Vendemiale G, et al. Gallbladder motility and cholesterol crystallization in bile from patients with pigment and cholesterol gallstones. Eur J Clin Invest. 2000;30:317-324.

54. Portincasa P, Moschetta A, Berardino M, et al. Impaired gallbladder motility and delayed orocecal transit contribute to pigment gallstone and biliary sludge formation in beta-thalassemia major adults. World J Gastroenterol. 2004;10:2383-2390.

55. Di Ciaula A, Garruti G, Wang DQ, Portincasa P. Cholecystectomy and risk of metabolic syndrome. Eur J Intern Med. 2018;53:3-11.

56. Garruti G, Wang DQ, Di Ciaula A, Portincasa P. Cholecystectomy: a way forward and back to metabolic syndrome? Lab Invest. 2018;98:4-6.

57. Gasbarrini A, Corazza GR, Gasbarrini G, et al. Methodology and indications of H2-breath testing in gastrointestinal diseases: the Rome Consensus Conference. Aliment Pharmacol Ther. 2009;29 (Suppl 1):1-49.

58. Kaur J, Rana SV, Gupta R, Gupta V, Sharma SK, Dhawan DK. Prolonged orocecal transit time enhances serum bile acids through bacterial overgrowth, contributing factor to gallstone disease. J Clin Gastroenterol. 2014;48:365-369.

59. Shoda J, He BF, Tanaka N, et al. Increase of deoxycholate in supersaturated bile of patients with cholesterol gallstone disease and its correlation with de novo syntheses of cholesterol and bile acids in liver, gallbladder emptying, and small intestinal transit. Hepatology. 1995;21:1291-1302.

60. Wu T, Zhang Z, Liu B, et al. Gut microbiota dysbiosis and bacterial community assembly associated with cholesterol gallstones in large-scale study. BMC Genom. 2013;14:669.
61. Keren N, Konikoff FM, Paitan Y, et al. Interactions between the intestinal microbiota and bile acids in gallstones patients. Environ Microbiol Rep. 2015;7:874-880.

62. Wang W, Wang J, Li J, et al. Cholecystectomy damages agingassociated intestinal microbiota construction. Front Microbiol. 2018;9:1402.

63. Van Erpecum KJ, Van Berge-Henegouwen GP. Gallstones: an intestinal disease? Gut. 1999;44:435-438.

64. van Erpecum KJ, Portincasa P, Gadellaa M, van deHeijning B, Renooij W, vanBerge-Henegouwen GP Effects of bile salt hydrophobicity on nucleation behaviour of cholesterol crystals in model bile. Eur J Clin Invest. 1996;26:602-608.

65. Di Ciaula A, Garruti G, Lunardi Baccetto R, et al. Bile acid physiology. Ann Hepatol. 2017;16:s4-s14.

66. Portincasa P, Di Ciaula A, Palmieri VO, Velardi A, vanBergeHenegouwen GP, Palasciano G. Impaired gallbladder and gastric motility and pathological gastro-esophageal reflux in gallstone patients. Eur J Clin Invest. 1997;8:653-661.

67. Dowling RH, Veysey MJ, Pereira SP, et al. Role of intestinal transit in the pathogenesis of gallbladder stones. Can J Gastroenterol. 1997;11:57-64.

68. Veysey MJ, Thomas LA, Mallet AI, et al. Prolonged large bowel transit increases serum deoxycholic acid: a risk factor for octreotide induced gallstones. Gut. 1999;44:675-681.

69. Van Berge-Henegouwen GP, Portincasa P, van Erpecum KJ. Effect of lactulose and fiber-rich diets on bile in relation to gallstone disease: an update. Scand J Gastroenterol Suppl. 1997;222:68-71.

70. Thomas LA, Veysey MJ, Bathgate T, et al. Mechanism for the transit-induced increase in colonic deoxycholic acid formation in cholesterol cholelithiasis. Gastroenterology. 2000;119:806-815.

71. Palasciano G, Portincasa P, Belfiore A, et al. Gallbladder volume and emptying in diabetics: the role of neuropathy and obesity. $J$ Intern Med. 1992;231:123-127.

How to cite this article: Di Ciaula A, MolinaMolina E, Bonfrate L, Wang DQ-H, Dumitrascu DL, Portincasa P. Gastrointestinal defects in gallstone and cholecystectomized patients. Eur J Clin Invest. 2019;49:e13066. https://doi.org/10.1111/eci.13066 